natural yearly rate of increase, by excess of births over deaths, while only 4.3 per thousand of the dwellers in houses, is 20.0 per thousand in the cottages; in other words, while the cottage pcpulation would double itself in thirty-five years, it would take the house population 165 years to achieve the same result. The apostles of birth-control have their field of activities sharply defined. One must not, however, forget that there is a migration from the cottages to the houses.

As compared with those living in houses the inhabitants of cottages have a death-rate larger by 30 per cent, a birth-rate larger by 126 per cent., and an infant mortality rate greater by I 84 per cent. One is perhaps inclined, without sufficient reason, to attribute the higher deathrate in the smaller dwellings entirely to defects in sanitary environment; there is no doubt that this will not explain the much greater difference in birth-rate, almost certainly due to difference in habits and not to variations in real fertility. But if the increased birth-rate is due to what may be called lack of foresight, it is to be expected that this same habit of mind, and others associated, will lead to an increased death-rate, and especially to a larger death-rate among infants. The infant mortality rate throughout the country has diminished from a figure of I 54 deaths per thousand births in 1900 to 80 in I920; has this been due to structural changes in the environment of the people, or has it not rather been due to improvement in the habits and customs of the mothers? Doubtless there is more sickness in the smaller dwellings attributable to germ-infested or stagnant air, but how much of this is due to the smaller rooms and more closely-built houses, and how much due to the custom of the closed window? It must always be worth while to better the structural environment, but improvement in the knowledge and practice of habits of health would lead to even greater results.

I hope that other medical officers of health whose districts afford them the opportunity will test the suggestions I have put forward. It is not to be expected that the rates existing among the cottages and houses in my area will be found unaltered elsewhere under different conditions, but it is possible that, with further knowledge, a general correction for the effects of social class may be evolved, a correction as easy of application as the official correction for age and sex, whereby, in making comparisons of the vital statistics of different localities, one would be able to exclude the effects, not only of varying age and sex constitution, but also of the differing social make-up of the populations.

\section{NOTES ON BACKWARD CHILDREN.}

BY

\section{J. J. Buchan, M.D., M.B., Ch.B., D.P.H., M.O.H., Bradford.}

The teachers in all the schools in Bradford have sent details of the number of cbildren whom they consider two years backward and more than two years backward. The total number of these children is 1,407 , of whom 1,040 are estimated to be two years backward and 367 more than two years backyard. These children are distributed pretty evenly over the city, but it is to be noted that there is an appreciably larger proportion in the poorer districts in the centre of the city and in the Southern part of the city. From an examination of the returns, it is quite clear that in the causation of this backwardness there are three main factors:-

1. Illness of the Child. This is the largest single cause, the children losing long periods of active educational work, throwing them some years behind the standard of children of the same age. Many of them have been at the open-air school and some at the cripple school. These are children of normal mentality whose opportunities for educational training have simply been curtailed by their illness. The advantage of instituting backward classes for these children is not particularly great, as they can with very little special attention rapidly take advantage of the present educational facilities offered. Frequently their recurring illness, howevet, maintains them in their backward educational state. It may be stated that at least 66 per cent. of the backwardness amongst the school children of Bradford is due to this class.

2. General Neglect and Bad Home Environmient. This is the second great cause which results in bad attendance of the child at school, thereby increasing its backwardness. The want of a sufficient home incentive makes the child careless and indifferent to its education, and this is particularly so in its later years of school attendance. There is no particular advantage in backward classes to these children who are backward 
from the bad home environment. They are normal mentally, and if the root cause of their backwardness were obviated, they could maintain their place easily with little special attention on the part of the teacher. It may be estimated that something under 25 per cent. of the children reported as backward from the schools are backward from this cause. As would be expected, this cause operates chiefly in the poorer districts of the town, and to a large extent gives rise to the apparent increased backwardness in these communities.

3. The last cause may be spoken of as intrinsic or idiopathic backwardness giving rise to slowness, dulness or stupidity in the child, and it would appear to account for something like 10 per cent. of the backwardness reported from the schools. This backwardness arises from either a delay in the mental development of the child or a greater or lesser degree of dulness or mental deficiency. It is this class of child who would be most benefited by the institution of backward classes. They are far from numerous, indeed the smallness of their number is rather remarkable.

\section{"FIVE YEARS' EXPERIENCE OF THE NO'TIFICATION OF PREGNANCY."*} BY

S. G. Moore, M.D., D.P.H., M.O.H., Huddersfield.

Milran Lecturer, 1916.

The figures which I will put before you are not sufficiently large to enable conclusive inferences to be made from them. On the other hand, they seem to have some value, and are submitted for what they are worth.

It may be interesting to explain how I approached the subject of the notification of pregnancy. Many years ago it came under my notice that the deaths of women in child bed occurred at the rate of from 3 to 6 per 1,000 births. Such a rate was not likely to materially affect the level of the general death rate, and for that reason 1 left the thing alone. During the weekly scrutiny of the death returns, from time to time entries excited my, interest from their pathetic character. I take it that none can view without feelings of grief and pity the death of a woman at the very period which is the consummation of her womanhooc: and when to that is added the knowledge that the calamity to herself and her family could readily have been prevented, these compassionate

* Read at Yorkshire Branch, Society M.O.H., Leeds, November 24th, 1921. feelings become poignant indeed. Eventually I was led to attempt something.

Because in the death returns there occurred regularly entries' which showed that human life was sacrificed under an existing system, it seemed to me that a change was called for. It may be regarded as an interference, but if it is an interference it is justified by the situation. The first manifest procedure was to get to know of the existence of paido-poietics at a sufficiently early period. The most direct method of doing this was to provide for their notification to the Sanitary Authority-hence the system. A lettercard as follows was introduced :-

County Borough of Huduersfield.

\section{NOTIFICATION OF PREGNANCY.}

To the Medical Officer of Health, Huddersfield,

After having obtained her consent to do so, I notify that $(a)$

of $(b)$

is expecting to be confined on or about ...........................192

Signed $(c)$

This notification should reach me within 7 days of engage= ment, otherwise fee will not be paid.

(a) Name of expectant mother.

(b) Postal address of expectant mother.

(c) Signature of notifier.

The woman is visited by a medical practitioner. In case of need the woman is advised to consult her family doctor. A copy of the report of the Assistant Medical Officer of Health who visited the case is sent to him, and the case is followed úp. Home-helps (housekeepers) and home-assistants (charwomen) are provided where such assistance is clearly required.

It is an essential condition precedent to the notification that the woman concerned should consent. The notification must not be asked for against her will. It lies in the hands of the Sanitary Authority to so conduct matters that the notifications and consequent ministrations are acceptable to the public whom they serve.

It should be observed that the visit from the Public Health Department is paid by a medical practitioner-not by a nurse, midwife or health visitor. I would sustain the objection of midwives and maternity nurses to their cases being visited by any less highly qualified person than a medical practitioner. I would not expect to receive notifications of pregnancy from them under such circumstances. I regard it as essential that the visit should be paid by a " doctor." 